\title{
Research on structural response when it is impacted
}

\author{
Ling Wang, Xiang Jiang, Lei Huang
}

\begin{abstract}
In this chapter, the collision process of two submersible vehicles is numerically simulated by finite element analysis method. Taking the crashed submersible as the research object, the collision response of the crashed submersible under the influence of collision parameters is considered.
\end{abstract}

Index Terms - cylindrical pressure structure; impact parameters; hysteresis

\section{INTRODUCTION}

Ship collision accidents always occur in the fluid environment. Therefore, the ship collision problem is a typical fluid-solid coupling problem (not only the huge force between the ship structures, but also the interaction between the hull structure and the fluid). Moreover, problems such as geometric nonlinearity and material nonlinearity are involved in the collision process of ships. Therefore, it is a very complicated problem for the study of ship collision, which involves many subject areas such as material science, rigid body dynamics, plastic dynamics, structural dynamics, fluid mechanics, and damage mechanics [1-2].

\section{SimUlation MODEL}

The colliding submersibles are of the same specification, and the state of the two submersibles at the time of collision is: the collision with the submersible is assumed to be a rigid body; The collision zone is located in the midship of the crashed submarine.

This simulation mainly studies the structural response of the crash-hit submarine, so the displacement constraint of the crash-hit submarine is no longer applied. Accordingly, the motion of the collided submersible under collision force belongs to transverse floating motion. It can be obtained from table 1.1 that the additional water mass coefficient of the collided submersible is 1.024 . The finite element model is shown in figure 1.1 .

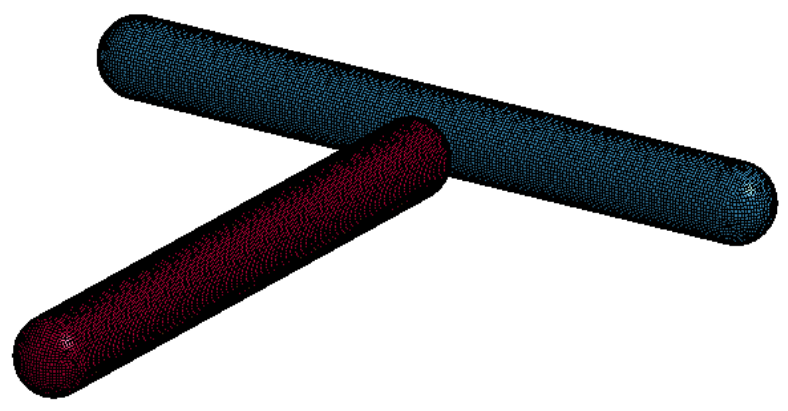

Fig1.1 Finite element model
Numerical simulation results and results analysis

\section{CAlCUlation SCHEME}

The calculation scheme is shown in table 1.1, and the impact position is shown in figure 1.1 Position A means that the impact position is on the ring frame, and position $B$ means that the impact position is between the two ribs.

Table.1.1 Computing scheme

\begin{tabular}{ccccc}
\hline $\begin{array}{c}\text { The } \\
\text { serial } \\
\text { number }\end{array}$ & $\begin{array}{c}\text { The } \\
\text { impact } \\
\text { location }\end{array}$ & $\begin{array}{c}\text { The } \\
\text { impact } \\
\text { Angle }\end{array}$ & $\begin{array}{c}\text { External } \\
\text { hydrostatic } \\
\text { pressure } \\
(\mathrm{MPa})\end{array}$ & $\begin{array}{c}\text { The impact } \\
\text { speed } \\
(\mathrm{m} / \mathrm{s})\end{array}$ \\
\hline $\begin{array}{c}\text { A } \\
2\end{array}$ & \begin{tabular}{c}
$\mathrm{B}$ \\
\hline
\end{tabular} & $90^{\circ}$ & 5 & 5 \\
\hline
\end{tabular}
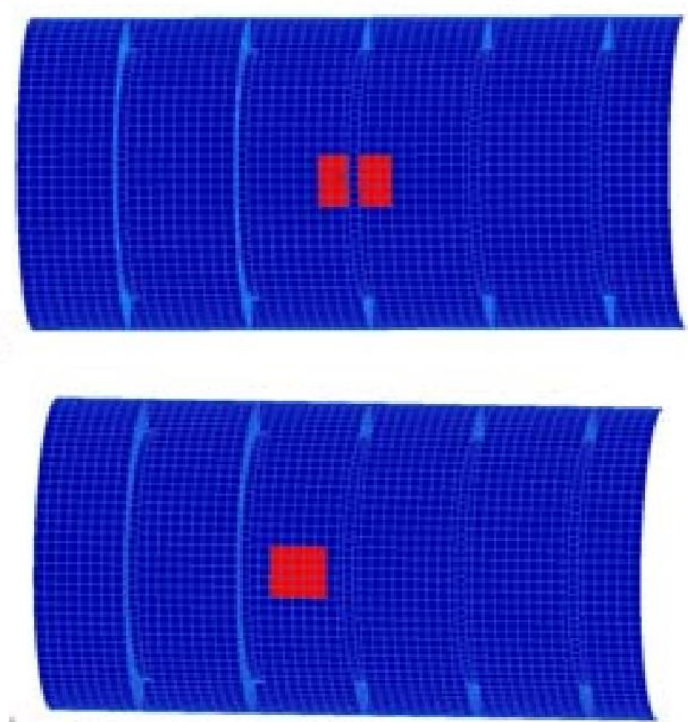

Fig.1.2 Impact position

Analysis of simulation results

Fig. 1.3 shows the stress distribution and deformation when striking the positions $\mathrm{A}$ and $\mathrm{B}$ of the cylindrical pressure-resistant structure. As can be seen from the figure, the high-stress area during the collision is mainly concentrated in the collision contact area, and a similar "circle" is formed with the first contact as the center, with the maximum stress at the center. When hitting position A, the stress on the shell of the pressure-resistant structure is smaller than that on the inner ring frame, with the maximum stress of 1.303E9Pa, and the maximum stress occurs at the contact of the ring frame collision. When the impact location is $\mathrm{B}$, the shell of the pressure-resistant structure is subjected to greater stress, with the maximum stress of $1.302 \mathrm{E} 9 \mathrm{~Pa}$. 
As can be seen from the deformation diagram, when the impact location is $\mathrm{A}$, the inner ring frame is the main stress member, and the web of the inner ring frame in the collision contact area fails due to the direct direct collision of the submersible at $\mathrm{A}$. When hitting position $\mathrm{B}$, the shell of the pressure-resistant structure at the beginning of contact was subjected to stress and deformation. As the collision continued, the impact submarine "squeezed" the internal ring ribs through the deformed shell. At this time, the impulse of the internal ring ribs was smaller than that of the direct direct impact, and the failure occurred at the shell first. It can be seen that the different collision location changes the failure order of components in the collision contact area.
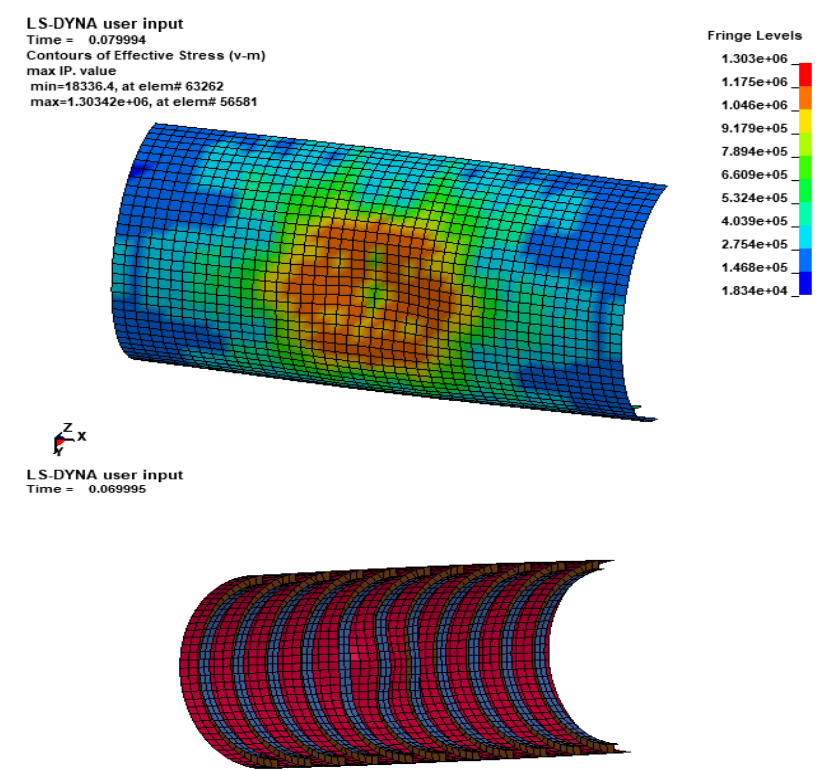

$\bar{x}^{2}$

(a) the maximum stress and deformation at the collision location $\mathrm{A}$
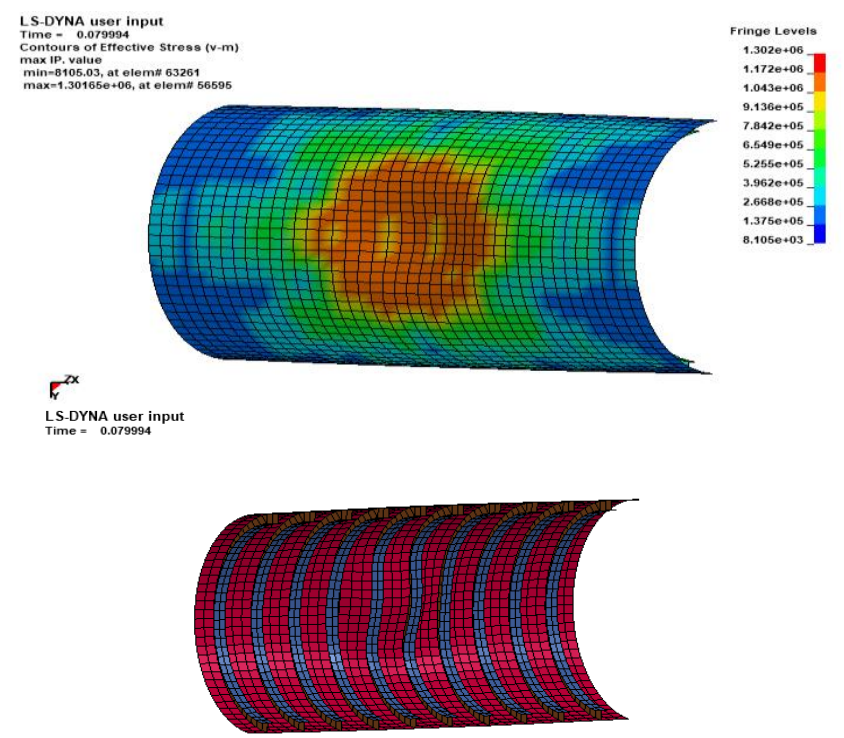

$T^{x}$

(a) the maximum stress and deformation at the collision location B

(b)

Fig.1.3 Stress distribution and deformation at A and B positions
Fig. 1.4 shows collision force curves under two collision contact positions. It can be concluded from the figure that the change trend of the collision force under the two collision positions is basically the same, but there are some differences. The force exerted by the collider at the collision position A is relatively uniform, and the collision force curve shows A relatively smooth trend[3-4]. When hitting position $B$, the shell rapidly deforms after collision contact, until the annular frame becomes the main load-bearing member, which shows a slow increasing trend of the impact force curve when the impact is $0.14 \mathrm{~m}-0.35 \mathrm{~m}$ deep. In general, the change of impact position makes the damage and deformation process of the submarine crash-hit vehicle different.

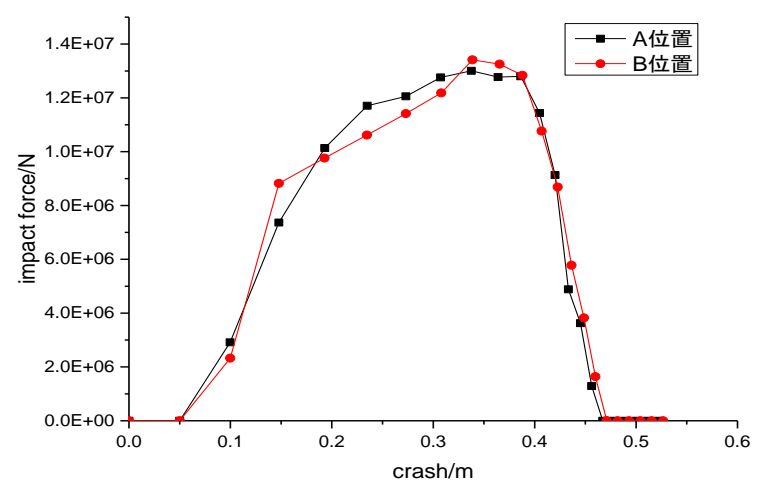

Fig.1.4 Impact force curve at impact A and B positions

Flig. 1.5 shows the impact of different impact positions on energy changes. On the whole, the change of the internal energy curve is not very big when striking positions A and B, which indicates that the different impact positions will not have A great impact on the energy absorption of the pressure resistant structure. The deformation and damage area of the structure determine the amount of energy absorption of the structure. Under the impact of position $B$, the overall deformation of the collision contact area of the pressure-resistant structure is relatively large, so the curve in the figure shows that the curve B is slightly higher than the curve $\mathrm{A}$ at the later stage of the collision.

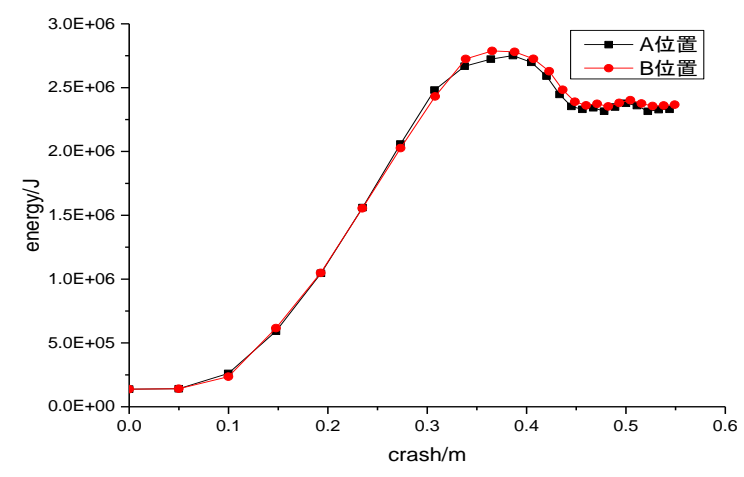

Fig.1.5 Impact of impact position on internal energy changes

The influence of impact angle

Calculation scheme

Table 1.2 is the calculation scheme to calculate the impact of different collision angles on the response of the collided submarine. Collision Angle refers to the included Angle formed by the longitudinal mid-section of the collider and the submersible. 
Table.1.2 Computing scheme

\begin{tabular}{ccccc}
\hline $\begin{array}{c}\text { The } \\
\text { serial } \\
\text { number }\end{array}$ & $\begin{array}{c}\text { The } \\
\text { impact } \\
\text { angle }\end{array}$ & $\begin{array}{c}\text { The } \\
\text { impact } \\
\text { location }\end{array}$ & $\begin{array}{c}\text { External } \\
\text { hydrostatic } \\
\text { pressure } \\
(\mathrm{MPa})\end{array}$ & $\begin{array}{c}\text { The impact } \\
\text { speed } \\
(\mathrm{m} / \mathrm{s})\end{array}$ \\
\hline 1 & $\begin{array}{c}30^{\circ} \\
45^{\circ}\end{array}$ & $\mathrm{A}$ & 5 & 5 \\
3 & $60^{\circ}$ & & & 5 \\
4 & $90^{\circ}$ & & & 5 \\
\hline
\end{tabular}

Analysis of simulation results

Fig. 1.6 shows collision force curves at four impact angles. As can be seen from the figure, the impact force curves under different impact angles are obviously different, and the main trend is that the maximum impact force increases with the increase of impact Angle. As shown in the figure, the maximum collision force is about $1.3 \mathrm{e} 7 \mathrm{n}$ when the included Angle of collision is $90^{\circ}$, which also indicates that the impact is most intense when the pressure-resistant structure is subjected to vertical impact. In the figure, the time when the maximum collision force appears varies from one curve to another, which indicates that the change of collision Angle changes the collision contact order and the intensity of collision of the members in the collision zone of the collider.

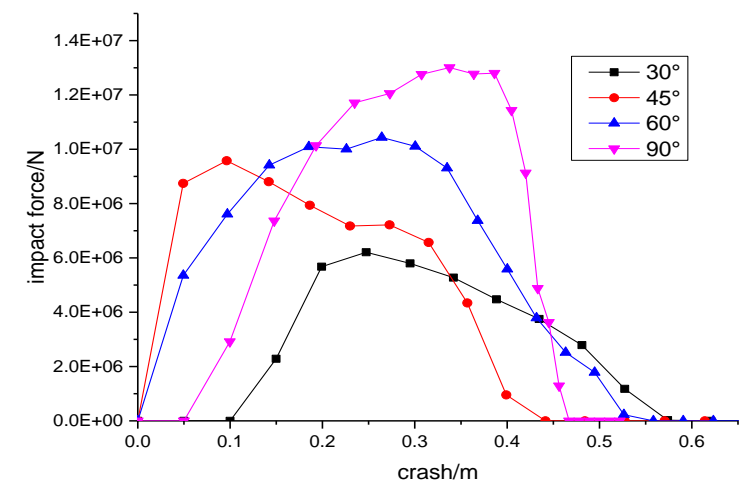

Fig.1.6.Collision force curve under different collision angles

Fig. 1.7 shows the change curve of energy under different impact angles. According to the figure, with the increase of the impact Angle, the internal energy of the crasered submarine gradually increases, and reaches the maximum when the collision is at $90^{\circ}$. The change of energy inside the crasered submarine can also reflect the deformation and damage of the crasered submarine. Therefore, a $90^{\circ}$ vertical collision is the most dangerous situation and should be avoided as far as possible[5].

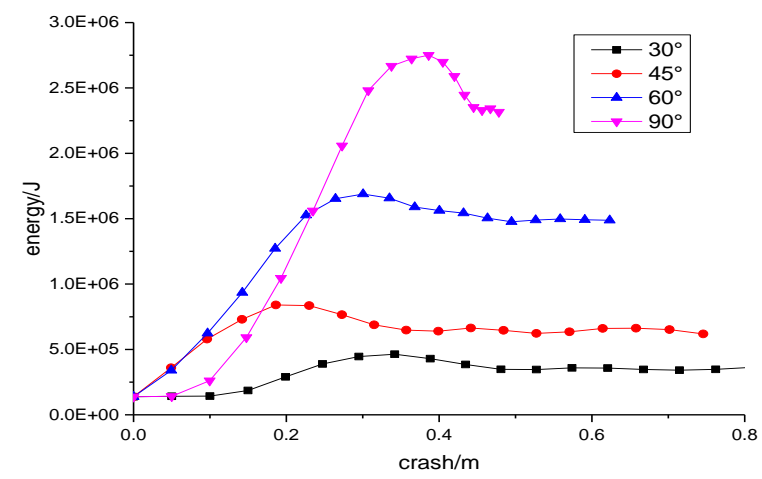

Fig.1.7 Energy variation curve at different collision angles Impact velocity calculation scheme

In this section, collision simulation calculation is carried out for the impact velocity of $1.5 \mathrm{~m} / \mathrm{s}, 3 \mathrm{~m} / \mathrm{s}, 4 \mathrm{~m} / \mathrm{s}$ and $5 \mathrm{~m} / \mathrm{s}$. The calculation scheme is shown in table 1.3.

Table.5.3 Computing scheme

\begin{tabular}{|c|c|c|c|c|}
\hline $\begin{array}{c}\text { The } \\
\text { serial } \\
\text { numbe }\end{array}$ & $\begin{array}{c}\text { The } \\
\text { impact } \\
\text { speed } \\
(\mathrm{m} / \mathrm{s})\end{array}$ & $\begin{array}{c}\text { The } \\
\text { impact } \\
\text { location }\end{array}$ & $\begin{array}{c}\text { External } \\
\text { hydrostatic } \\
\text { pressure } \\
(\mathrm{MPa})\end{array}$ & $\begin{array}{c}\text { The impact } \\
\text { angle }\end{array}$ \\
\hline 1 & $1.5 \mathrm{~m} / \mathrm{s}$ & \multirow{4}{*}{ A } & \multirow{4}{*}{ 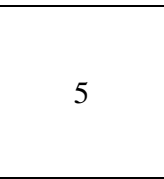 } & \multirow{4}{*}{$90^{\circ}$} \\
\hline 2 & $3 \mathrm{~m} / \mathrm{s}$ & & & \\
\hline 3 & $4 \mathrm{~m} / \mathrm{s}$ & & & \\
\hline 4 & $5 \mathrm{~m} / \mathrm{s}$ & & & \\
\hline
\end{tabular}

Analysis of simulation results

Figure 1.8 and 1.9 respectively show the curves of impact force and energy changes at different impact speeds. The change of impact velocity is the change of initial kinetic energy of the collision system. The higher the impact velocity is, the higher the initial kinetic energy is[6]. It can be seen from Fig. 1.8 that, with the increase of impact velocity, the maximum impact force becomes larger and the impact contact time becomes longer. This is because it takes relatively more time for the crash-hit submarine to accelerate under a higher impact velocity, until the speed of the crash-hit submarine is the same as that of the impact submarine. It can be seen from figure 1.9 that the trend of energy change curve under different impact speeds is basically the same, which indicates that different impact speeds do not significantly change the deformation and damage order of the collision contact area of the submarine collider[7]. And the internal energy absorption increases with the increase of velocity, indicating that the deformation area of shell and internal ring frame in the collision contact area increases with the increase of velocity.

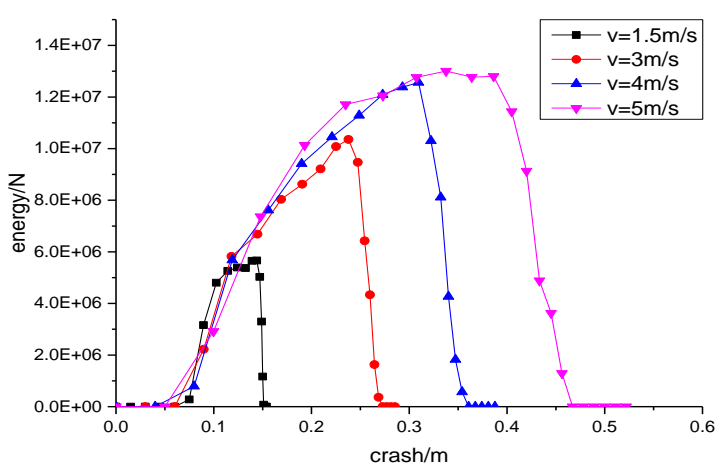

Fig.1.8 Collision force curve at different impact speeds

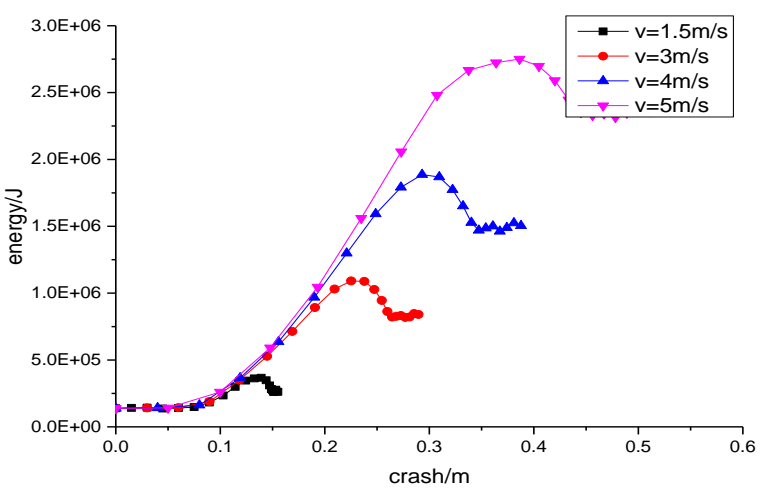

Fig.1.9 Energy curve at different impact speeds 
The effect of external hydrostatic pressure calculation scheme

The calculation scheme is shown in table 1.4. Other parameters remain unchanged except the change of external hydrostatic pressure. The impact position is that the midship of the submersible is opposite to the ring frame, and the impact speed is $5 \mathrm{~m} / \mathrm{s}$.

Table.1.4 Computing scheme

\begin{tabular}{ccccc}
\hline $\begin{array}{c}\text { The } \\
\text { serial } \\
\text { numbe }\end{array}$ & $\begin{array}{c}\text { External } \\
\text { hydrostatic } \\
\text { pressure } \\
(\mathrm{MPa})\end{array}$ & $\begin{array}{c}\text { The } \\
\text { impact } \\
\text { location }\end{array}$ & $\begin{array}{c}\text { The impact } \\
\text { speed }(\mathrm{m} / \mathrm{s})\end{array}$ & $\begin{array}{c}\text { The impact } \\
\text { angle }\end{array}$ \\
\hline 1 & 1 & & & \\
2 & 3 & & 5 & $90^{\circ}$ \\
3 & 5 & $\mathrm{~A}$ & & \\
4 & 8 & & & \\
5 & 10 & & & \\
\hline
\end{tabular}

Analysis of simulation results

Fig. 1.10 shows the stress distribution and damage deformation of the impact contact area of the pressure-resistant structure under different external hydrostatic pressure[8]. It can be concluded from the figure that, with the increase of external hydrostatic pressure, the maximum stress in the collision contact area gradually increases, that is, the existence of external water pressure makes the pressure-resistant structure have some prestress before the collision contact. The greater the external water pressure is, the greater the prestress will be, which will increase the overall stress level. According to the damage and deformation diagram, as the external hydrostatic pressure increases, the deformation area of the collision contact area becomes larger and larger. When the temperature reaches $10 \mathrm{MPa}$, the failure of the web of ring frame appears, indicating that the external hydrostatic pressure will work with the deformation of the structure, aggravating the structural deformation of the collision contact area[9].
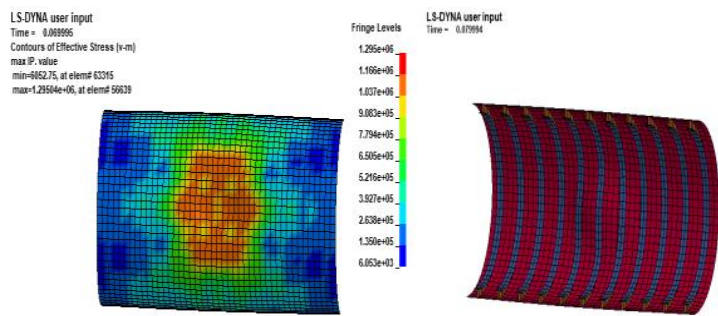

$7^{x}$

$L$

(a) The maximum stress and damage deformation when the external water pressure is $1 \mathrm{MPa}$
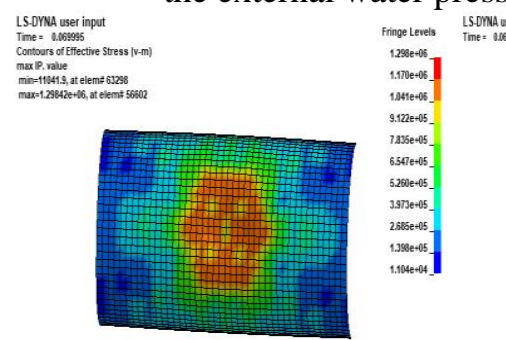

$7^{x}$

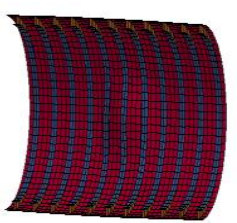

$\stackrel{x}{4}$

(b) The maximum stress and damage deformation when the external water pressure is $3 \mathrm{MPa}$

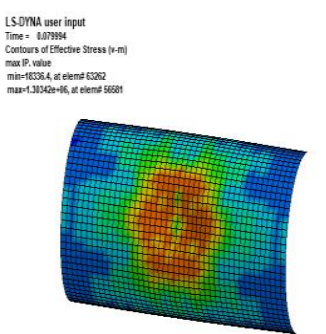

$h^{2 x}$

(c) The maximum stress and damage deformation when the external water pressure is $5 \mathrm{MPa}$

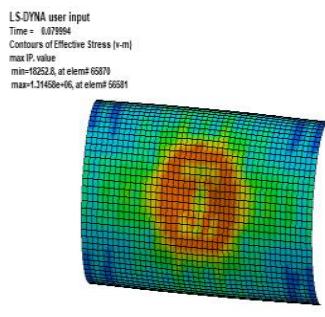

$f^{x}$

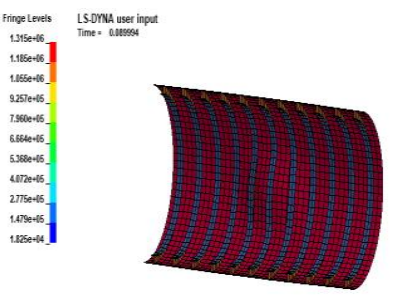

$\stackrel{4}{x}$

(d) The maximum stress and damage deformation when the external water pressure is $8 \mathrm{MPa}$

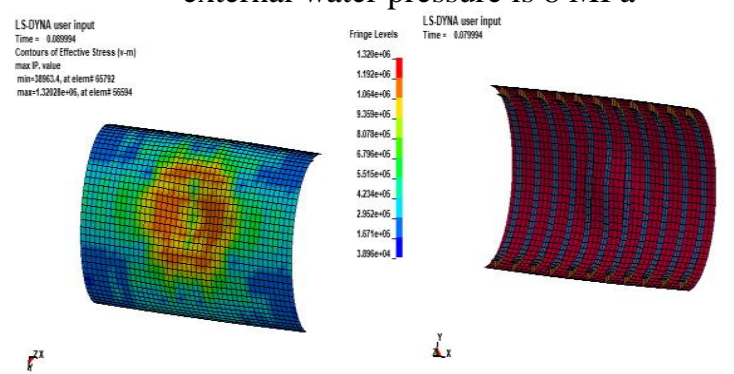

(e) The maximum stress and damage deformation when the external water pressure is $10 \mathrm{MPa}$

Fig.1.10 Stress distribution and deformation under different external hydrostatic pressures.

Figure 1.11 and figure 1.12 respectively reflect the impact of different external hydrostatic pressure on collision force and energy. It can be concluded from fig. 1.11 that the variation trend of the impact force curve under various water pressure is basically consistent, indicating that the change of external hydrostatic pressure does not change the structural deformation and failure order of the impact contact area of the pressure-resistant structure. As the collision progresses, the collision force gradually increases until the impact depth is $0.33 \mathrm{~m}$, when the collision force under different hydrostatic pressure reaches the maximum value. At this time, the annular frame bearing most of the bearing capacity deforms or fails, and then the collision force gradually decreases. It can be found that, with the increase of external hydrostatic pressure, the value of maximum collision force keeps decreasing, indicating that the existence of external hydrostatic pressure reduces the severity of collision to some extent. As can be seen from figure 1.12, the existence of external hydrostatic pressure makes the pressure-resistant structure have an initial internal energy between collision contact, and the initial internal energy increases with the increase of external hydrostatic pressure. And the external water pressure does work with the deformation of the structure. With the increase of the external water pressure, the internal energy of the crassible increases faster. 


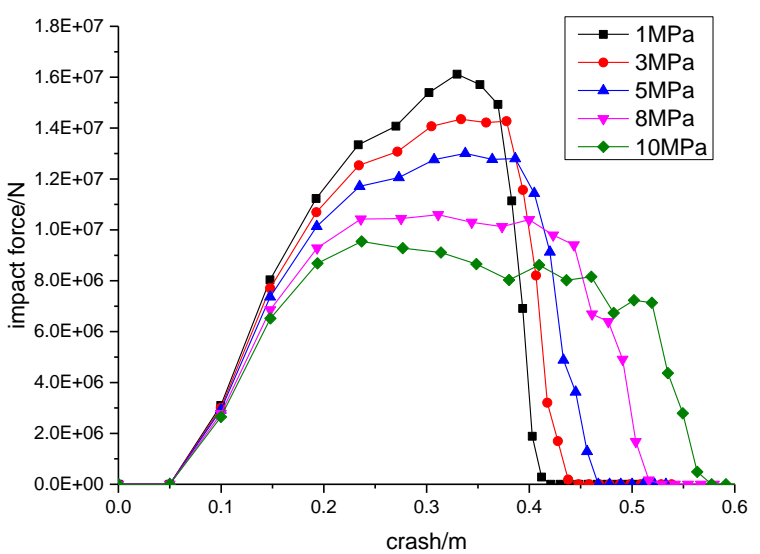

Fig.1.11 Collision force curve under different external hydrostatic pressure

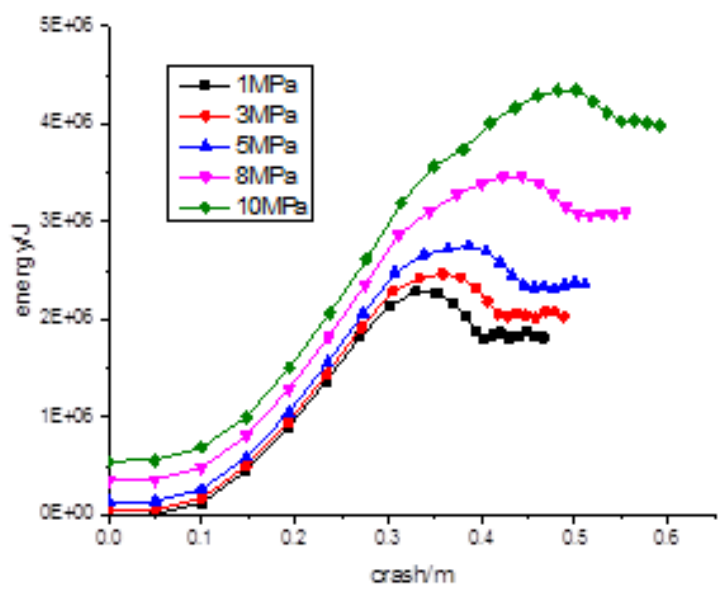

Fig.1.12 Internal energy change diagram under different external hydrostatic pressures

In this paper, finite element software is used to simulate the collision process of two submersible vehicles, and the impact of different impact parameters on the collision response of the submerged vehicle during the collision process is systematically studied. On this basis, the hysteresis characteristics of the impact pressure-resistant structure are discussed[10].

\section{CONCLUSION}

When the pressure-resistant structure is impacted, the annular ribs are the main load-bearing and energy-absorbing members In order to reduce the deformation and damage of the submersible when it is impacted, the strength of the annular ribs should be strengthened to improve their energy-absorbing capacity.

\section{REFERENCE}

[1] Weicheng Cui, Junhou Pei, Wei Zhang. Simple and accurate solution for calculating stresses in conical shells[J]. Computer and Structures, 2001:265-279.

[2] Donner R. Besiner F. Sourne L.Numerical Simulation of Ship-submarine Collision[M].8th International Symposium on Practical Design of Ships and Other Floating Structures, 2001,2:1309-1314.

[3] Gregory K. Failure Modeling of Titanium 6Al-4V and Aluminum 2024-T3 with the Johnson-Cook Aaterial Model: DOT/FAA/AR-03/57.
Washington,D. C: National Technical Information Service,2003: 1-11. [4] Tiwari G, Iqbal M A, Gupta P K, et al. The Ballistic Resistance Ofthin Aluminium Plates with Varying Degrees of Fixity Along the Ircumference.International Journal of Impacting Engineering,2014: 74: 46-56.

[5] Gao Y, Hu Z, Ringsberg J W. An Elastic-plastic Ice Material Model for Ship-iceberg Collision Simulations[J].Ocean Engineering,2015,102:27-39

[6] Zienkiewicz O C. Coupled problems and their numerical so lution in: Lew is R W , Bettess P, H inton Eeds. Numerical Methods in Coupled Systems. JohnWiley and Sons Ltd, New York (1984)

[7] Haskind MD. The hydrodynamic theory of ship oscillations in rolling and pitch ing. P rik 1. Mat. Mekh. 10 (1946) : 33-66.

[8] Hask indMD. The oscillation of a ship in stillwater. I z v. A kad. N auk S S S R. , O td. Tekh. Nauk 1 1946 : 23-34.

[9] Bishop RED, Price WG. Hydroelastic of Ships[C]. Camb. Univ. Press,Cambridge, 1979.

[10] Newman JN. The theory of ship motions. Advances in Applied Mechanics. 18 (1978) : 221-283 